\title{
Atopy and wheeze in children according to parental atopy and family size
}

\author{
JOHN B DAVIS AND CHRISTOPHER J BULPITT \\ From Lister House, Group Practice Centre, Harlow, Essex and the Department of Medical Statistics \\ and Epidemiology, London School of Hygiene and Tropical Medicine, London
}

ABSTRACT The relationship between atopy and wheeze was examined in children, together with the possible influence on these conditions of parental atopy and family size. Children with a repeated history of wheezing were selected from an urban general practice population. The children, their first degree relatives, and a control group were examined for atopic status, atopy being defined as more than one positive immediate skin prick test response. The prevalence of wheeze in boys was $15 \cdot 5 \%$, in girls $7 \cdot 6 \%$, and of atopy in boys $19 \cdot 7 \%$ and in girls $8.1 \%$. Of 110 atopic children $70 \%$ had no atopic parent, $27 \%$ had one atopic parent, and in $3 \%$ both parents were atopic. The presence of parental atopy was associated with an increased prevalence of wheeze in boys but not in girls, $12.0 \%$ of boys having a history of wheezing if neither parent was atopic and $27.5 \%$ if either or both parents were atopic $(\mathrm{p}<0.05)$. The presence of parental atopy was associated with an increased prevalence of atopy in girls but not in boys, $6 \cdot 1 \%$ of girls having atopy if neither parent was atopic and $18.9 \%$ if either or both parents were atopic $(\mathrm{p}<0.01)$. There was a strong association between atopy and wheeze for both sexes and no statistically significant difference in the prevalence of atopy or wheeze in children whether they were from two, three, or four child families.

Considerable interest surrounds the relationship between genetic and environmental factors in determining wheeze in children. Most authors suggest a multifactorial hypothesis. ${ }^{1-4}$ It is also clear that at least up to puberty there is a male preponderance in the prevalence of wheeze. ${ }^{5}$

In this study we examined the influence of parental atopy upon the prevalence of atopy and wheeze in children. We also examined the influence of family size as several studies had noted an association between membership of large families and an increased prevalence of wheeze. ${ }^{6-11}$ One of us has previously conducted a population survey of atopy and wheeze in an urban sample of asthmatic children and their families. ${ }^{12}$ In the present communication we examine these data according to parental atopy and family size.

\section{Methods}

We defined wheezy children as those in whom two or more attacks of wheeze occurred in two or

Address for reprint requests: Dr JB Davis, Lister House, Staple Tye, Harlow, Essex CM18 7LU. more years. We defined atopy as the capacity of an individual to respond with an immediate reaction to prick testing with two or more allergens from two or more major groups of allergen.

The population comprised a general practice of 845 families, 520 of whom had one or more children aged 15 years or under. Wheezy subjects were detected by means of a questionnaire to which there was a $90 \%$ response. Wheezy morbidity was confirmed from the medical records kept by JBD over the previous 10 years. One hundred and eighteen wheezy subjects were identified in 111 families. A control group of families was selected by taking every third family from the residue of 375 families. The wheezy and control groups were tested for type 1 allergic responses by skin testing parents and children with 20 different allergens. They were grouped as follows: pollens, moulds, foods, house-dust mite, and domestic animals. Each individual was allocated to one of two groups: group 1-negative or single positive; group 2-multiple positive. Thirteen per cent of the children were not skin tested as they refused the test or failed to attend the clinic. 
Five per cent of parents were not skin tested. The reported data on the prevalence of atopy and wheeze considers only families in which all members had been skin tested for atopy.

Estimates of the true population prevalence of atopy and wheeze were obtained by multiplying the control sample by a factor of three.

The prevalence of atopy and wheeze was also calculated for boys and girls according to family size. One child families were excluded because of small numbers and there were only 10 families with more than four children in the wheezy population. They produced 17 wheezy children. The control population yielded one family with six children and none with five. The families with five or six children were therefore excluded from this examination of data because of the lack of a comparable control population. The family sizes compared thus consisted of two, three, and four children.

The chi-squared test was used to test the association between the categories of parental atopy and the prevalence of atopy and wheeze in children. Likewise the observed and expected prevalence of atopy and wheeze were tested for each family size. Allowance was made in the statistical analysis for the fact that only one-third of the control population had been examined.

\section{Results}

PREVALENCE OF WHEEZE

Table 1 gives the prevalence of wheeze by parental atopy. Wheeze was twice as common in boys as in girls $(p<0.01)$. The presence of parental atopy was associated with an increased prevalence of wheeze in children, 9.8\% when neither parent was atopic, and $18.7 \%$ when either or both parents were atopic $(p<0.001)$. The association with paternal atopy was not significantly different from the association with maternal atopy. Considering girls and boys separately the presence of parental atopy was associated with an increased prevalence of wheeze in boys, $12 \%$ when neither parent was atopic, $27.5 \%$ when either or both parents were atopic $(\mathrm{p}<0.05)$; this was not demonstrable for girls (neither parent atopic $7.5 \%$, either or both parents atopic $8 \cdot 1 \%$ ).

\section{PREVALENCE OF ATOPY}

Table 2 gives the prevalence of atopy according to parental atopy. Atopy was twice as common in

Table 1 Prevalence of wheeze by parental atopy

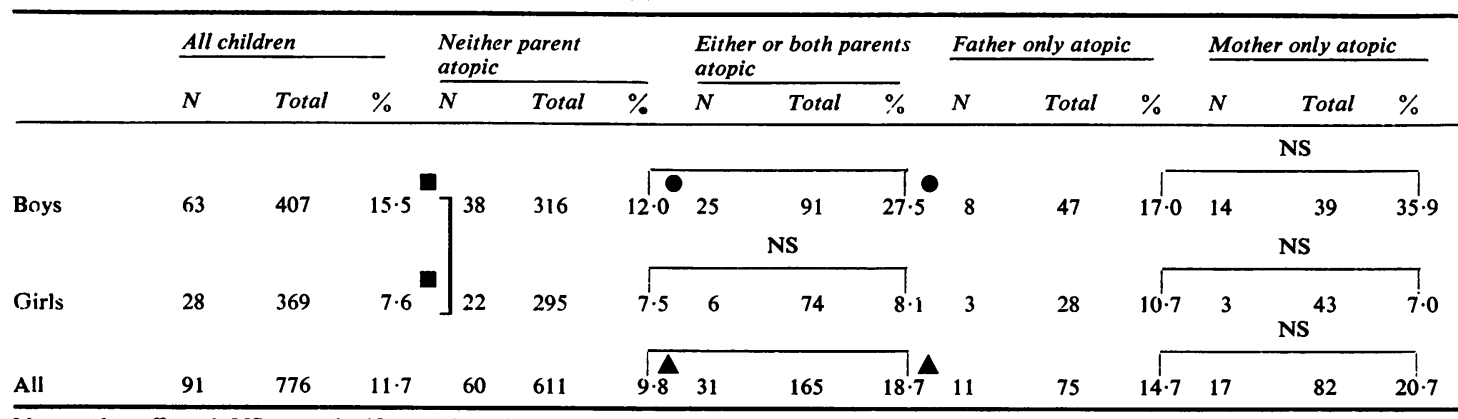

$\mathrm{N}=$ number affected; $\mathrm{NS}=$ not significant, $\Delta \mathrm{p}<0.001, \mathrm{a}=\mathrm{p}<0.01,0 \mathrm{p}<0.05$.

Table 2 Prevalence of atopy by parental atopy

\begin{tabular}{|c|c|c|c|c|c|c|c|c|c|c|c|c|c|c|c|}
\hline & \multicolumn{3}{|c|}{ All children } & \multicolumn{3}{|c|}{ Neither parent atopic } & \multirow{2}{*}{\multicolumn{3}{|c|}{$\begin{array}{l}\text { Either or both parints } \\
\text { atopic }\end{array}$}} & \multicolumn{3}{|c|}{ Father only atopic } & \multicolumn{3}{|c|}{ Mother onlv atopic } \\
\hline & \multirow[t]{2}{*}{$N$} & \multirow[t]{2}{*}{ Total } & \multirow[t]{2}{*}{$\%$} & \multirow[t]{2}{*}{$N$} & \multirow[t]{2}{*}{ Total } & \multirow[t]{2}{*}{$\%$} & & & & \multirow[t]{2}{*}{$N$} & \multirow[t]{2}{*}{ Total } & \multirow[t]{2}{*}{$\%$} & \multirow[t]{2}{*}{$\bar{N}$} & \multirow[t]{2}{*}{ Total } & \multirow[t]{2}{*}{$\%$} \\
\hline & & & & & & & $N$ & Total & $\%$ & & & & & & \\
\hline & & & & & & & & $\mathbf{S}$ & & & & & & & \\
\hline \multirow[t]{2}{*}{ Boys } & 78 & 407 & $19 \cdot 2$ & 59 & 316 & $18 \cdot 7$ & 19 & 91 & 20.9 & 14 & 47 & $29 \cdot 8$ & 4 & 39 & $10 \cdot 3$ \\
\hline & & & & & & & & & & & & & \multicolumn{3}{|c|}{ NS } \\
\hline Girls & 32 & 369 & $8 \cdot 7$ & 18 & 295 & $6 \cdot 1$ & 14 & 74 & $18 \cdot 9$ & 6 & 28 & $21 \cdot 4$ & 6 & $S^{43}$ & $14 \cdot 0$ \\
\hline All & 110 & 776 & $14 \cdot 2$ & 77 & 611 & $12 \cdot 6$ & 33 & 165 & $20 \cdot 0$ & 20 & 75 & $26 \cdot 7$ & 10 & 82 & $12 \cdot 2$ \\
\hline
\end{tabular}

Abbreviations and symbols as in table 1 
boys as in girls $(\mathrm{p}<0.05)$. The presence of parental atopy was associated with an increased prevalence of atopy in childen, $12.6 \%$ when neither parent was atopic, $20 \%$ when either or both parents were atopic $(p<0.05)$. The association with paternal atopy was not significantly different from the association with maternal atopy. When considering boys and girls separately the presence of parental atopy was associated with an increased prevalence of atopy in girls, $6.1 \%$ when neither parent was atopic, $18.9 \%$ when either or both parents were atopic, $(\mathrm{p}<0.01)$. This was not statistically significant for boys, $18.7 \%$ when neither parent was atopic, $20.9 \%$ when either or both parents were atopic.

\section{INFLUENCE OF FAMILY SIZE}

Table 3 reports the prevalence of atopy and wheeze for families with two, three, and four children. The highest prevalence was observed in families with four children but the difference did not reach statistical significance. There was no significant difference in prevalence according to whether the children came from two child or three child families.

\section{Discussion}

We considered the following questions. Does parental atopy influence the prevalence of atopy and wheeze in children, and if so in what manner? What is the extent and the nature of the relationship between atopy and wheeze? Is there a relationship between family size and the prevalence of atopy and wheeze? These questions are examined in the context of existing hypotheses as to genetic and environmental factors in the pathogenesis of atopy and wheeze.

Our working definition of atopy was based upon two or more type 1 allergic responses to a batch of 20 allergens. It should be admitted that other authors usually regard a single positive test as evidence of atopy. However, Sibbald and Turner-
Warwick $^{13}$ use the multiple sensitive individual in describing a polar group of extrinsic asthmatics. The correlation of type 1 responses with IgEmediated responses in certain individuals provides the theoretical basis for the use of the prick test as an epidemiological instrument in a survey of atopy. ${ }^{14}$

The overall prevalence of wheeze in boys of $15.5 \%$, and in girls of $7.6 \%$ agrees with recent estimates from other population studies if categories such as wheezy bronchitis are included. ${ }^{15} 16$ The overall prevalence of atopy in boys was $19.7 \%$ and in girls $8.1 \%$. In a study of 7000 twin pairs Edford Lubs ${ }^{2}$ predicted in figures for estimated prevalence that $6 \%$ of allergic children have no parent with allergy, $30 \%$ one parent only, and both parents are allergic in 3\% of individuals. These figures are similar to those found in the present study where in $70 \%$ of atopic children neither parent was atopic, in $27 \cdot 3 \%$ either mother or father was atopic, and in $2.7 \%$ both parents were atopic (additional table available from the authors on request). There was a strong association between atopy and wheeze in the children. The observed prevalence of wheezy atopic subjects was three times the expected level.

The influence of parental atopy led to a near two-fold increase in wheeze or atopy in the children of a parent with atopy. However, the presence of parental atopy was associated with an increase in the prevalence of wheeze in boys but not in girls. The presence of parental atopy was also associated with an increase in the prevalence of atopy in girls but not in boys. When one or more parent had atopy the prevalence of atopy plus wheeze (a child with both conditions) was increased only 1.7 times. This somewhat poor association between atopic wheeze and parental atopy has been demonstrated by other authors. TurnerWarwick $^{3}$ compared the prevalence of a positive family history (first degree relatives) for hayfever, eczema, and asthma in skin test positive and skin test negative asthmatics. In the skin test positive subjects she found an excess prevalence of hay-

Table 3 Family size and prevalence of atopy and wheeze

\begin{tabular}{|c|c|c|c|c|c|c|c|c|c|c|}
\hline \multirow[t]{3}{*}{ Family size } & \multicolumn{5}{|l|}{ Boys } & \multicolumn{5}{|l|}{ Girls } \\
\hline & \multirow{2}{*}{ Total } & \multicolumn{2}{|c|}{ Atopv } & \multicolumn{2}{|c|}{ Wheeze } & \multirow{2}{*}{ Total } & \multicolumn{2}{|c|}{ Atopy } & \multicolumn{2}{|c|}{ Wheeze } \\
\hline & & $N$ & $\%$ & $N$ & $\%$ & & $N$ & $\%$ & $N$ & $\%$ \\
\hline $\begin{array}{l}\text { Two children } \\
\text { Three children } \\
\text { Four children }\end{array}$ & $\begin{array}{r}212 \\
130 \\
58\end{array}$ & $\begin{array}{l}39 \\
20 \\
16\end{array}$ & $\begin{array}{l}18 \cdot 4 \\
15 \cdot 4 \\
27 \cdot 6\end{array}$ & $\begin{array}{l}33 \\
20 \\
12\end{array}$ & $\begin{array}{l}15 \cdot 6 \\
15 \cdot 4 \\
20 \cdot 7\end{array}$ & $\begin{array}{r}157 \\
134 \\
68\end{array}$ & $\begin{array}{r}12 \\
8 \\
9\end{array}$ & $\begin{array}{r}7 \cdot 6 \\
6 \cdot 0 \\
13 \cdot 2\end{array}$ & $\begin{array}{r}12 \\
10 \\
7\end{array}$ & $\begin{array}{r}7 \cdot 6 \\
7 \cdot 5 \\
10 \cdot 3\end{array}$ \\
\hline
\end{tabular}

$\mathrm{N}=$ number affected; Total = total number 
fever and eczema but not of asthma. Nevertheless Sibbald and Turner-Warwick ${ }^{13}$ reported an excess prevalence of asthma among these first degree relatives.

We found that children with atopy and wheeze, wheeze without atopy, and atopy without wheeze, occur in roughly equal numbers. Wheeze may be present in the child or adult in the absence of atopy, and also in the absence of parental atopy. As such, it may reflect the capacity of the airways to be affected by environmental influences alone. Likewise atopy may be present in the absence of wheeze and of parental atopy. It expresses the capacity of the body to respond to environmental influences, sometimes independently but often in association with wheeze. Presumably both genetic and environmental factors are important.

The sex of the child affects the prevalence of atopy and wheeze even in the absence of a parental influence. These sex differences may be lost after puberty. ${ }^{5}$ It is possible that the main contribution to the $2: 1$ sex difference for wheeze in children derives from the finding that prepubertal girls did not experience an excess of wheeze when their parents were atopic. This would occur if hormonal changes at puberty allow genetic influences to be expressed.

Atopy was equally prevalent in mothers and fathers. There was no significant difference in the association of maternal rather than paternal atopy, with prevalence of wheeze or atopy in their children. However, there was a non-significant trend for atopy to be less common in children (especially boys) with atopic mothers. We considered that this was caused by chance, but sex-linked genetic influence could not be ruled out, nor the unlikely possibility that an atopic mother protects her children from common allergens.

Several studies implicate family size as an associated feature of wheezy morbidity. Leigh and Marley ${ }^{1}$ found fewer first degree relatives of control than asthma individuals. This was because of smaller family size in the former group. Dawson et $a l^{6}$ found a higher incidence of asthma in second children and that children with severe asthma came from larger families. Holland ${ }^{7}$ found family size was one of four factors determining reduced peak flow rate in children. This was possibly independent of a previous history of pneumonia, bronchitis, and asthma. Colley ${ }^{8}$ on the other hand, in a review article, notes the difficulty of isolating factors such as family size from other environmental factors. McNicholl and Williams, ${ }^{9}$ while finding no link with parental age or rank, found a correlation with the membership of large families. One of us ${ }^{10}$ likewise found no correlation with parental age or rank in the family but asthmatics showed an apparent increase in frequency in larger families. Finally Sims et $a l^{11}$ found the differences between their control and bronchiolitis groups were only that the number and age of siblings was greater in the latter. In examining the prevalence of atopy and wheeze by family size we found that the apparent preponderance of atopy and wheeze in larger families related directly to the number of children in those families. Given the overall prevalence rates of atopy and wheeze the trend was a function of those rates but an increase in families with four or more children could not be excluded with confidence.

Most current hypotheses for the genetic basis of atopy and wheeze invoke a multifactorial influence. These are summarised by several authors. ${ }^{1-4}$ Evidence is drawn from population, family, and twin studies. All emphasise environmental factors as major determinants both of the prevalence of atopy and wheeze, and of the expression of a genetically determined trait. Our data fit this view.

The possibility of a separate genetic basis for the inheritance of atopy and wheeze is reviewed by Turner-Warwick. ${ }^{3}$ She draws evidence from studies of intrinsic and extrinsic asthma. We document a trend for the inheritance of atopy in children which is expressed differently in boys and girls. Thus the trend for wheeze in boys does not follow the trend for atopy. This difference may, however, be merely that of expression-determined in some way by the sex of the child. If sex differences in the prevalence of atopy disappear at puberty and do not prevail in adult life this argument is supported.

This paper derives from material in a thesis submitted by JBD and approved by the University of London for the degree of MD. The original work was supported by a grant from the Asthma Research Council. We wish to thank Mrs B Sibbald, Research Fellow Cardiac Thoracic Unit, Brompton Hospital, London, for her critical contribution.

\section{References}

1 Leigh D, Marley E. Bronchial asthma. Oxford: Pergamon Press, 1967.

2 Edfords-Lubs ML. Allergy in 7000 twin pairs. Acta Allergol 1971; 26:249-85.

3 Turner-Warwick M. Immunology of the lung. London: Arnold, 1978.

4 Cohen C. Genetic aspects of allergy. Med Clin North Am 1974; 58:25-42. 
5 Crawford WA, Beedham CG. The changing demographic pattern in asthma related to age and sex. Med J A ust 1976; 1:430-4.

6 Dawson B, Horobin G, Illsley R, Mitchell R. Childhood asthma in Aberdeen. Lancet 1969; 1:827-30.

7 Holland WW, Halil T, Bennett AE, Elliott A. Factors influencing the onset of chronic respiratory disease. Br Med J 1969; 2:205-8.

8 Colley JRT. Respiratory disease in childhood. Br Med Bull 1971; 27:9-13.

$9 \mathrm{McNichol} \mathrm{KN}$, Williams HB. Asthma in children. 1. Clinical and physiological components. $\mathrm{Br}$ Med J 1973; 4:7-11.

10 Davis JB. Asthmatic children and their families. MD thesis, University of London, 1975:104-5.
11 Sims DG, Downham MAPS, Gardner PS, Webb JKG, Weightman D. Study of 8 year old children with a history of respiratory syncytial virus bronchiolitis in infancy. Br Med J 1978; 1:11-13.

12 Davis JB. Asthma and wheezy bronchitis in children. Clin Allergy 1976; 6:329-38.

13 Sibbald B, Turner-Warwick M. Factors influencing the prevalence of asthma among first degree relatives of extrinsic and intrinsic asthmatics. Thorax 1979; 3:332-7.

14 Pepys J. Laboratory methods in clinical allergy. Proc $R$ Soc Med 1972; 65:271-2.

15 Clark TJH, Godfrey S, eds. London: Chapman and Hall, 1977.

16 Kuzemko JA, ed. Asthma in children. London: Pitman Medical, 1976. 